\title{
Corrigendum
}

\section{Objective assessment of tumour response to therapy based on tumour growth kinetics}

\section{E Mehrara, E Forssell-Aronsson and P Bernhardt}

British Journal of Cancer (20II) 105, 1468. doi:I0.1038/bjc.20II.436 www.bjcancer.com

(C) 20II Cancer Research UK

Correction to: British Journal of Cancer (2011) 105, 682-686. doi:10.1038/bjc.2011.276

During the final editing of the above paper before its publication, errors were, unfortunately, introduced in equations 5 and 7 . In both the equations, a minus sign had been deleted. The correct equations are now shown below.

Equation 5:

$$
\mathrm{TR}=-\ln \left(\frac{V_{\mathrm{t}}}{V_{\mathrm{n}}}\right)
$$

Equation 7:

$$
\mathrm{TR}=-\ln \left(\frac{V_{\mathrm{t}}}{V_{\mathrm{d}}}\right)+\mathrm{SGR}_{0} \cdot \Delta t=\mathrm{LR}+\mathrm{Err}
$$

The authors and publishers apologise for any inconvenience this may have caused. 